\title{
Eve teasing as a form of violence against women: A case study of District Srinagar, Kashmir
}

\author{
Chesfeeda Akhtar \\ Department of Sociology, University of Kashmir, J and K, India, 190006.
}

Accepted 20 June, 2013

\begin{abstract}
Eve teasing is a ridiculous form of enjoyment for men and a physical as well as mental torment for women. This is one of the daily problems women in Indian society face. Of all the forms that violence against women can assume, eve teasing is the most ubiquitous and insidious because it is considered normal behaviour and not an assault to females. This paper provides an analysis of the magnitude of eve teasing and its relation to age, socio-economic and psychological factors. It also examines women's responses to this type of violence. Administering 300 structured and pre-tested interview schedules on women through stratified random sampling, the paper concludes that eve teasing is rampant and it grabs a girl's childhood from her while teaching her to learn to avoid victimization irrespective of the social class to which she belongs. And, it concludes that there is a correlation between eve-teasing and the profile of its perpetrators and, certain psychological factors are also related to this type of violence. Moreover, women's responses to eve teasing are more of endurance than of resistance for the fear of double victimisation.
\end{abstract}

Key words: Eve teasing, violence, offenders' profile, psychological factors, women's responses, Kashmir.

\section{INTRODUCTION}

Violence against women is experienced by women of all ages and social classes, all races, religions and nationalities, all over the world. It is overwhelmingly perpetrated by men (Krug et al., 2002). It is the most pervasive violation of human rights in the world today. Its forms are both subtle and blatant and its impact on development is profound. But it is so deeply embedded in cultures around the world that it is almost invisible (Bunch, 1997). Violence against women is a manifestation of the historically unequal power relations between men and women, which have led to domination over and discrimination against women by men and to the prevention of full advancement of women (United Nations, 1993). The United Nations Declaration on Violence against Women provides a basis for defining gender-based violence. According to Article 1 of the Declaration, violence against women is to be understood as:

"Any act of gender-based violence that results in, or is likely to result in, physical, sexual or psychological harm or suffering to women, including threats of such acts, coercion or arbitrary deprivations of liberty, whether occurring in public or private life".

The experience or threat of violence affects the lives of millions of women worldwide, in all socio-economic and educational classes, cutting across boundaries of wealth, race, religion and culture; thus violating and impairing women's enjoyment of their human rights and fundamental freedoms. Every form of violence threatens all women and limits their ability to make choices about their lives. At a recent 12- country workshop held in China on 
women's non-formal education, participants were asked to name the worst aspect of being female. Fear of male violence was the almost unanimous answer (Heise, 1992).

Acts or threats of violence, whether occurring within the home or in the community; being perpetrated or condoned by the State instil fear and insecurity in women's lives and are obstacles to the achievement of equality, development and peace. The fear of violence, including harassment, is a permanent constraint on the mobility of women and limits their access to resources and basic activities. High social, health and economic costs to the individual and society are associated with violence against women. Violence against women impoverishes society economically, politically and culturally, by limiting the active role that women can make in the development of their community. Violence against women is one of the crucial social mechanisms by which women are forced into a subordinate position compared with men.

Of all the forms that violence against women can assume, eve teasing is the most ubiquitous and insidious as it is considered 'normal' behaviour and not an assault to females. It is so commonplace that often we have become desensitized to offensive behaviours.

Eve teasing is a euphemism used in India for sexual harassment or molestation of women by men. It ranges in severity from sexually colored remarks to outright groping. The term eve-teasing is used to refer to sexual harassment of women in public places such as the streets, public transportation, parks, beaches, and cinema halls. This type of public harassment by a lone man or gangs of men includes verbal assaults such as making passes or unwelcome sexual jokes; nonverbal assaults such as showing obscene gestures, winking, whistling, and staring; and physical assaults such as pinching, fondling, and rubbing against women in public places ("Eve-teasing," 1999; Stevens, 1984 cited in Ramasubramayam and Beth 2003). In addition, in several instances eve-teasing has been followed by more violent assaults such as rape and murder. Eve teasing is a ridiculous form of enjoyment for men and a physical as well as mental torture for women. This is one of the daily problems women in Indian society face. It happens everywhere irrespective of a woman's socio-economic or educational background.

Every single day of their lives, women face what can only be described as a systematic assault on their fundamental right to free movement and right to personal dignity. The sexual harassment that women are subjected to on the streets, buses and in other public places constitute a serious infringement of women's basic rights which are unique to them. The only comparable situation is the continuous indignities which Harijans (untouchables) face in the course of their normal daily existence. Women and Harijans who were traditionally grouped together by men continue to share a bond in contemporary India - both are denied free movement and the right to personal dignity (Mehrotra, 1982).

Eve teasing acts as a control on women by repressing their general mobility in and accessibility to public spaces, thereby affecting their sense of personhood and security. As Shah writes, "for women learning to avoid being hustled in the street is as much a part of living in the city as learning to cope with public transportation" (Shah, 2000). The UN Special Rapporteur on Violence against Women views eve teasing as;

"A personal attack on women's minds and bodies, instilling fear and violating a woman's right to bodily integrity, education and freedom of movement. It is utilized as a powerful mechanism of control and intimidation, through which women's subordinate social status is maintained. The immeasurable damage to a woman's self-esteem and the subsequent avoidance of public places by single women could hardly take us on the way to achieving gender equality."

The variables that give rise to sexual violence in India are undoubtedly numerous and complex. Gender biased socialization and social control at the family and societal level is at the root of sexual violence against women. The discrepancy between the norms, values, expectations and sanctions imposed on girls and those on boys because of the socially structured gender inequality is a critical factor. Men are given unlimited freedom right from childhood, sanctions are imposed only on girls and almost none on boys; there is no accountability for boys and if their parents come to know about their being eve teasers they take it so lightly that it becomes an object of humour for them. Therefore eve teasing can be perceived as an outgrowth of the gender biased socialization process and a mechanism by which men assert power and dominance over women.

Media plays a significant role in shaping notions about gender roles and gender identities within the Indian context. It is the cultural framework within which people get their cue. The portrayal of violence against women in any of the media - advertising, films, and newspaper reporting of sexual offences - is one of the most insidious as well as one of the most effective ways of showing where power lies in our society. It lies in the hands of the image-makers-men. To accept the media makers' excuse that 'we are not creating reality we are only reflecting it' is to accept that violence against women is a fundamental part of the relationship between the sexes (thus deserving accurate 'reflection'), rather than a symptom of the way men and women are taught to view each other 
(Davis et al., 1987).

\section{REVIEW OF LITERATURE}

The report of a study conducted by the Gender Study Group of the University of Delhi showed that in 1996, 91.7 per cent of all inmates of women's hostels and 88.2 per cent of all women day scholars had faced sexual harassment on the roads within the campus. The report says, "Molestation is possible because its violent face is masked by its deceptive stage name, 'eve-teasing'. In India, sexual harassment has been disguised, made to appear harmless, by its name; the term 'teasing' conveys the apparently harmless intention of the act, successfully veiling the pernicious violence lying behind the mask. The term, 'eve', deflects attention away from the perpetrators onto the victim 'eve', who, through the process of naming, is pictured as '... a temptress who seduces or provokes men...' (Gender Study Group, 1996).

A study sponsored by UNICEF and Save the Children Fund in the Indian subcontinent showed that the film medium is influential, especially with teenage boys, in teaching notions about masculinity, power, and violence in relationships with women (Poudyal, 2002).

\section{METHODOLOGY}

\section{The study area}

The study area of this research work is District Srinagar of Kashmir Province in $\mathrm{J} \& \mathrm{~K}$ State. Although the biography of Kashmir is strikingly different from the rest of India, woman in the traditional Kashmiri society lived like her sister communities in other parts / cultures of the Indian sub-continent. She equally shared the sorrows and fortunes of life. Although the practice of infanticide, foeticide, and dowry deaths were not resorted to, women were generally abused, maltreated, subjugated and physically victimized right from their childhood because of the socially structured inequality. Physical violence against women was prevalent among all social strata but the women belonging to lower social strata were victimized of sexual abuse also; thus writes Kapur, "In Kashmir not only were the girls kidnapped for the purpose of prostitution but also sold by their poor parents themselves to the owners of the ill fame. In Srinagar there were many houses of ill-repute. The most notorious places in Srinagar, where prostitution was carried on, were however the houseboats "the floating houses of ill-fame". These were mostly visited by the foreign visitors, especially the bachelors who often contracted a dreadful disease which occasionally proved fatal. E.J. Sandys, a missionary visitor to Kashmir thus wrote to British Residence on 18 June, 1916; "In returning my pass for travelling in Kashmir, may I be allowed to say that our pleasure in the beauties of Kashmir would have been far greater had we not had so many evidences of the abominable custom of procuration of women, who are freely offered to visitors to Kashmir (Kapur, 1992).

The various processes of change, like the process of modernization, have not succeeded to cut at the root of the traditional values and attitudes of the people towards women. Rather, the changing social structure, which exposed the Kashmiri women (belonging to all social strata) to outside world, has made them more vulnerable to all types of sexual abuse. They are subjected to the abuses like sexual harassment, molestation, eveteasing and even to immoral trafficking, kidnapping, abduction and rape. Especially during the conflict situation in Kashmir a striking increase in the sexual violence against women has been witnessed. While entire communities suffer the consequences of armed conflict and terrorism, women and girls are particularly affected because of their status in society and their sex.

Tables 1 and 2 present the statistical figures of crime against women in Kashmir Zone and Srinagar District, respectively. These figures represent only a part of the actual victimisation of women as was stated by the SHO Women's Police Station Rambagh, "Most of the cases of wife beating and dowry are resolved at our level by counselling and thus are prevented from undergoing further trial". Moreover, such cases are not reported by the victims because many of the abused women do not want their husbands to be prosecuted and also for the fear of humiliation and censure from family and community. Further, sexual violence is even more underreported mainly for the fear of being stigmatised and reprisal from the offender. Therefore, these police records are an underestimation of the extent of violence against women in Kashmir.

\section{Methods and techniques used}

Data for the study were collected through both the quantitative as well as the qualitative methods by canvassing interview schedules, carrying out focus group discussions and observation. Interview schedules, carefully prepared and pretested, were administered to 300 respondents belonging to different age groups, educational and occupational categories (Tables 3 to 5). The required sample was selected through stratified random sampling. Stratification was made on the basis of age and occupational status of women which facilitated the distribution of the sample into different educational categories. Then the required sample was randomly selected among these strata. However, stratified random sampling was preceded by judgment sampling; the judgment was made that the most vulnerable group of women to this type of violence is that which comes out of the homes either for the purpose of earning or for attaining education.

After the data were collected, codebooks were developed, based on the responses in the interview schedules. Thereupon, the data in all the schedules, which had been duly filled in, were coded. The coded data were processed using the SPSS package. The task included feeding in the data, verification, computation, validation and presentation of tables to facilitate data analysis and interpretation. The quantitative data were then ready for interpretation. The interpretation of the data was carried out keeping in view the overall perspective of the study. Efforts were made to achieve a harmonious blend of quantitative and qualitative data. The most vulnerable age group of women and worst hit by sexual violence is 15-25 years; therefore, this age group comprised $30 \%$ of the sample followed by $25-35$ years age group which was $29 \%$; while $35-45$ years age group represented $22 \%$ and above 45 years comprised $19 \%$ of the sample selected. In order to ensure a representative character of the sample, different occupational categories were included in which major representation (50\%) was given to the student category as it is worst hit by sexual violence; 
Table 1. Statistical figures of crime against women in Kashmir Zone for the year 2003, 2004 and 2005 up to November.

\begin{tabular}{lllll}
\hline $\mathbf{S} / \mathbf{N}$ & Crime Head & \multicolumn{3}{c}{ Years } \\
\cline { 3 - 5 } & & $\mathbf{2 0 0 3}$ & $\mathbf{2 0 0 4}$ & $\mathbf{2 0 0 5}$ \\
\hline 1. & Eve teasing & 251 & 156 & 271 \\
2. & Molestation & 798 & 869 & 704 \\
3. & Kidnapping & 480 & 459 & 467 \\
4. & Rape & 97 & 123 & 104 \\
5. & Cruelty by husband & 8 & 16 & 12 \\
\hline
\end{tabular}

Source: Police Records, Crime Branch IGP's Office, District Police Headquarters, Batamalo, Srinagar.

Table 2. Statistical figures of crime against women in District Srinagar from the year 2000 up to the November 2005.

\begin{tabular}{llcccccc}
\hline S/N. & Crime head & \multicolumn{7}{c}{ Years } \\
\cline { 3 - 8 } & & $\mathbf{2 0 0 0}$ & $\mathbf{2 0 0 1}$ & $\mathbf{2 0 0 2}$ & $\mathbf{2 0 0 3}$ & $\mathbf{2 0 0 4}$ & $\mathbf{2 0 0 5}$ \\
\hline 1. & Eve teasing & 142 & 88 & 86 & 130 & 55 & 165 \\
2. & Molestation & 137 & 207 & 270 & 249 & 261 & 205 \\
3. & Kidnapping & 106 & 101 & 106 & 91 & 92 & 92 \\
4. & Rape & 11 & 09 & 24 & 23 & 24 & 16 \\
5. & Cruelty by husband & - & 04 & 12 & 06 & 17 & 10 \\
6. & Immoral trafficking act & 01 & - & 01 & - & 05 & 02 \\
\hline
\end{tabular}

Source: Police Records, Crime Branch SSP's Office, District Police Headquarters, Batamalo, Srinagar.

Table 3. Age distribution of the respondents.

\begin{tabular}{llcc}
\hline S/N & Age groups & No. of respondents & $\%$ \\
\hline 1. & $15-25$ & 90 & 30 \\
2. & $25-35$ & 87 & 29 \\
3. & $35-45$ & 66 & 22 \\
4. & 45 and above & 57 & 19 \\
Total & & 300 & 100 \\
\hline
\end{tabular}

Table 4. Occupational distribution of the respondents.

\begin{tabular}{llcc}
\hline S/N & Occupation & No. of respondents & $\%$ \\
\hline 1. & Students & 150 & 50 \\
2. & Non-gazetted & 75 & 25 \\
3. & Gemployees & 75 & 25 \\
Total & & 300 & 100 \\
\hline
\end{tabular}

$25 \%$ sample was selected from those in non-gazetted jobs and another $25 \%$ was selected from those in gazetted jobs. The sample
Table 5 Educational distribution of the respondents.

\begin{tabular}{|c|c|c|c|}
\hline $\mathbf{S} / \mathbf{N}$ & Educational qualification & $\begin{array}{l}\text { No. of } \\
\text { respondents }\end{array}$ & $\%$ \\
\hline 1. & Matric and $10+2$ & 51 & 17 \\
\hline 2. & Graduation & 105 & 35 \\
\hline 3. & PG and above & 144 & 48 \\
\hline Total & & 300 & 100 \\
\hline
\end{tabular}

comprising student category was selected from different higher secondary schools, colleges and university. This distribution of the sample into different occupational categories divided the sample into the following educational groups: $17 \%$ matriculates and those pursuing higher secondary courses, 35\% graduates and those pursuing graduate courses and $48 \%$ with P.G.and above qualifications and those pursuing P.G. courses and research.

\section{FINDINGS AND DISCUSSION}

As is evident from Tables 6 and 7,100\% respondents reported having faced eve-teasing, in some or other forms, irrespective of their socio-economic background 
Table 6. Incidence of eve-teasing.

\begin{tabular}{llll}
\hline S/N. & Responses & No. of respondents & $\%$ \\
\hline 1. & Yes & 300 & 100 \\
2. & No & 0 & 0 \\
Total & & 300 & 100 \\
\hline
\end{tabular}

Table 7. Age of respondents when teased for the first time.

\begin{tabular}{lccl}
\hline S/N & Age & No. of respondents & $\%$ \\
\hline 1. & $14-16$ & 207 & 69 \\
2. & $16-18$ & 50 & 16.7 \\
3. & $18-20$ & 43 & 14.3 \\
Total & & 300 & 100 \\
\hline
\end{tabular}

Table 8. Place of facing eve-teasing.

\begin{tabular}{llll}
\hline S/N & Places & Frequency & $\%$ \\
\hline 1. & In busy markets and buses & 300 & 100 \\
2. & Inside and outside educational institutions & 300 & 100 \\
3. & At picnic spots & 300 & 100 \\
4. In social gatherings (marriages etc.) & 300 & 100 \\
Total no. of respondents & 300 & 100 \\
\hline
\end{tabular}

and age. Majority of the respondents (69\%) had first suffered eve teasing at the ages of $14-16$, and $16.7 \%$ respondents had this experience at the ages of $16-18$; while $14.3 \%$ respondents reported having been teased for the first time at the ages of $18-20$. These findings suggest that eve teasing is a bitter experience that a woman suffers as soon as she leaves childhood; her childhood is snatched from her when she is victimised for the first time and made to realize that she has to learn to avoid being victimised. Eve teasing is one of the daily problems that every woman has to face irrespective of the social class to which she belongs.

When inquired about the frequency and intensity of this abuse, common threads could be identified in the abused women's descriptions of facing this abuse throughout their life; they moved through various stages of abuse, whose duration and intensity depended on various stages of their age; while teenage respondents reported having been subjected to intense abuse (especially verbal and gestural abuse). As the frequency and intensity of verbal and gestural teasing tended to decrease with increasing age, there was no significant decrease in the frequency and intensity of physical abuse especially on buses; it was only at the stage of their middle age that the frequency as well as the intensity of physical abuse got significantly diminished.
Being a multiple response question, the figures in Table 8 represent the frequency of responses; as there is not particular place for eve teasers to commit this offence, they commit it wherever they find a woman. From the table it is revealed that women are not safe in any social setting; they are denied free movement wherever they go. They are victimised on buses, busy markets, inside and outside educational institutions, at picnic spots and are not spared even in social gatherings like marriages etc.

The above evidence suggests that eve teasing happens everywhere and it happens regardless of where one is studying, what her designation is, or to which social class she belongs.

Being a multiple response question, the figures in the Table 9 represent the frequency of responses as women experience multiple types of eve teasing at the hands of men. The figures reveal that physical intimacy on buses and on busy roads / markets and the other types of eve teasing like, singing obscene songs, unwelcome sexual jokes, remarks about female body, showing obscene gestures, winking, whistling, staring and stalking are the types of abuse which $100 \%$ respondents reported having suffered from, though with varying degrees at different stages of their life. $21 \%$ respondents reported being abused by obscene and suggestive words uttered on the 
Table 9. Type of eve-teasing suffered from.

\begin{tabular}{llll}
\hline S/N & Type of eve-teasing & Frequency & $\%$ \\
\hline 1. & Physical intimacy in buses and on busy roads / markets & 300 & 100 \\
2. & Obscene songs, unwelcome sexual jokes and remarks about female body & 300 & 100 \\
3. & Showing obscene gestures, winking, whistling, staring and stalking & 300 & 100 \\
$4 . \quad$ Obscene and suggestive words uttered (or messages sent) on the telephone or & 63 & 21 \\
5. & Forced and outright groping (molestation) & 3 & 1 \\
Total no. of respondents & 300 & 100 \\
\hline
\end{tabular}

telephone or by obscene messages sent on the cell phones or through internet. Only $1 \%$ respondents reported incidents of molestation (forced and outright groping) despite that, police records of molestation cases show its incidence is much higher in Srinagar District.

Therefore, it can be concluded that other respondents tended to underreport such incidents for the obvious reason that it would attach stigma to them and would be embarrassing for them to report such incidents. According to police sources, molestation or even eve teasing cases are rarely reported by the victims themselves who usually manage to escape the situation; such cases either come directly to the notice of the policemen on duty or are reported by nearby people. All these (3 respondents) reported single incidents of molestation and all of them reported being assaulted, in busy markets, by middle aged persons who from their physical appearance looked like having low socio-economic and educational background and who after committing the offence had escaped from the spot taking advantage of the crowded market. As reported by these abused women, they themselves had somehow managed to escape from the spot avoiding seeking help of nearby people or reporting to the police. Moreover, neither of them had informed their family members about the incident because it would have been embarrassing to discuss such matters with their family members and, it would have only aggravated their problem by troubling their family members who in distress might have imposed unlimited restrictions on their social life; and further, there was some apprehension that their family members might have found faults with their behavior to have "invited" the abuse, as reported by these abused women.

The perception of women about the relationship of the type of eve-teasing and the offenders profile like their age group, socio-economic and educational background is reflected in Table 10.100\% respondents were of the view that verbal and gestural teasing (like obscene songs, unwelcome sexual jokes, remarks about female body, showing obscene gestures, winking, whistling, staring and stalking) is mostly perpetrated by teenagers and young adults; while $16.7 \%$ respondents included middle aged people also among such offenders. Therefore, teenagers and young adults ranked highest among the offenders of verbal and gestural teasing followed by middle aged people.

Whilst $100 \%$ respondents viewed that verbal and gestural teasing is mostly committed by people apparently belonging to low socio-economic and educational background, a majority among them (83\% respondents) were of the view that such offences are committed by apparently men belonging to high socio-economic and educational background also.

Regarding the physical assault, which is mostly committed stealthily on buses and busy markets, middle aged men were placed highest in the rank of its perpetrators by $100 \%$ respondents; while $19 \%$ among them were of the view that young adults and teenagers also commit such offences, though young adults were reported to perpetrate this abuse more than teenagers.

Moreover, $100 \%$ respondents placed men, who are apparently uneducated and of low socio-economic background, highest in the rank of the offenders of physical teasing, whereas $21.3 \%$ respondents among them were of the view that men who are apparently educated and of high socio-economic background also commit such offences.

The above empirical evidence suggests that while men belonging to all age groups and socio-economic and educational backgrounds may constitute the perpetrators of sexual violence against women, there is a close association between age, educational and socioeconomic factors and the nature of violence; younger age is associated with greater verbal and gestural teasing perpetration and victimisation, and its frequency tends to decrease with increasing age. Verbal and gestural eveteasing is much glorified by media and the message sent is that it is more desirable and suitable for teenagers and young adults, but humorous and ridiculous if committed by middle aged people. But diminishing frequency of 
Table 10. Profile of offenders.

\begin{tabular}{|c|c|c|c|c|}
\hline $\mathrm{S} / \mathrm{N}$ & Profile & Categories & Frequency & $\%$ \\
\hline \multirow{2}{*}{1.} & \multirow{3}{*}{$\begin{array}{l}\text { Age groups to which offenders of verbal and } \\
\text { gestural eve-teasing mostly belong }\end{array}$} & Teenagers and Young adults & 300 & 100 \\
\hline & & Middle aged also & 50 & 16.7 \\
\hline Total & & & 300 & 100 \\
\hline \multirow{2}{*}{2.} & \multirow{2}{*}{$\begin{array}{l}\text { Type of offenders of verbal and gestural eve- } \\
\text { teasing }\end{array}$} & $\begin{array}{l}\text { Apparently belonging to low socio-economic } \\
\text { and educational background }\end{array}$ & 300 & 100 \\
\hline & & $\begin{array}{l}\text { Apparently belonging to high socio-economic } \\
\text { and educational background also }\end{array}$ & 249 & 83 \\
\hline Total & & & 300 & 100 \\
\hline \multirow{2}{*}{3.} & \multirow{3}{*}{$\begin{array}{l}\text { Age groups to which offenders of physical } \\
\text { eve-teasing mostly belong }\end{array}$} & Middle aged & 300 & 100 \\
\hline & & Young adults and teenagers also & 57 & 19 \\
\hline Total & & & 300 & 100 \\
\hline \multirow{2}{*}{4.} & \multirow{2}{*}{ Type of offenders of physical eve-teasing } & $\begin{array}{l}\text { Apparently belonging to low socio-economic } \\
\text { and educational background }\end{array}$ & 300 & 100 \\
\hline & & $\begin{array}{l}\text { Apparently belonging to high socio-economic } \\
\text { and educational background also }\end{array}$ & 64 & 21.3 \\
\hline Total & & & 300 & 100 \\
\hline
\end{tabular}

verbal and gestural teasing is replaced by the escalation in physical teasing (committed stealthily on buses and on busy roads) as the perpetrators enter middle age. A positive association between physical teasing perpetration and middle age is apparent in the above findings.

Whilst eve teasing occurs across all social and economic groupings, the- findings show a significant association between physical teasing and the low educational and social status of perpetrators; but as far as the verbal and gestural teasing is concerned, men belonging to all educational and socio-economic backgrounds tend to perpetrate this type of violence, though there is evidence that men of lower socioeconomic and educational status tend to perpetrate more frequent and demeaning violence than their higher status counterparts.

Table 11 represents the different strategies that were employed by the victims of eve teasing in different situations that they were used to confront with and had become a way of life for them. Majority of respondents $(95.7 \%)$ said that they usually let the verbal or gestural teasing to go unrecognized, and only a small percentage of respondents $(4.3 \%)$ reported their retaliation in the event of verbal or gestural teasing. $59 \%$ respondents reported retaliation to physical teasing, and $41 \%$ respondents said that in the event of physical teasing, the strategy they employed was to remain silent and somehow managing to escape the situation to protect themselves. These coping strategies to protect oneself from the abuse make women feel like living in a prison created by the eve teasers, who are, of course men.

As is shown in Table 12, the women who did not retaliate to verbal or gestural teasing referred to many factors for employing this strategy - most important reason which $100 \%$ of them cited was that retaliation would only invite humiliation and embarrassment for them and people would put blame on them for having done "something wrong" to invite the eve teaser for committing the offence. Retaliation, in their opinion, would not protect them from the violence because it is a matter of daily affair - they may get rid of the eve teaser at a particular point of time but how long? The eve teasers are present everywhere; how many of them can a woman be expected to confront? $96.2 \%$ respondents among them feared that retaliation might provoke reprisal from the offender which would be detrimental for the victim. So they thought that it was better to endure it silently to prevent the risk of their double victimisation. $66.2 \%$ respondents perceived that verbal or gestural teasers like to be rebuked and they always try to extract response from the victim because they take silence wrongly as the message of approval on part of the victim which encourages them for further teasing.

Physical teasing is usually experienced on buses and busy markets. $100 \%$ respondents who had never retaliated to this kind of abuse feared embarrassment and 
Table 11. Women's responses to eve teasing.

\begin{tabular}{llcc}
\hline S/N & Women's responses & No. of respondents & $\%$ \\
\hline 1. & Let the verbal or gestural teasing go unrecognized & 287 & 95.7 \\
2. & Retaliate to verbal or gestural teasing & 13 & 4.3 \\
Total & & 300 & 100 \\
& & 177 & 59 \\
1. & Retaliate to physical teasing & 123 & 41 \\
2. & Somehow manage to escape the situation of physical teasing & 300 & 100 \\
Total & & & \\
\hline
\end{tabular}

Table 12. Reasons for not retaliating to verbal or gestural teasing.

\begin{tabular}{llcc}
\hline S/N & Reasons & Frequency & $\%$ \\
\hline 1. & Retaliation would mean inviting humiliation and embarrassment and & 287 & 100 \\
& even might result in the reversal of blame on the victim herself & & \\
2. & Fear of reprisal from the offender & 276 & 96.2 \\
3. & Giving response to it encourages offenders & 190 & 66.2 \\
Total no. of respondents & 287 & 100 \\
\hline
\end{tabular}

Table 13. Type of retaliation.

\begin{tabular}{llcc}
\hline S/N & Type of retaliation & Frequency & $\%$ \\
\hline 1. & Rebuke offender of physical assault & 177 & 100 \\
2. & Rebuke offenders of both types of abuse & 13 & 7.3 \\
Total no. of respondents & 177 & 100 \\
\hline
\end{tabular}

humiliation especially where the offender escapes responsibility due to hustle of jam-packed buses and markets and the offender might even reverse the blame on the victim that she was asking for it and when the man (offender) refused to comply, she accused him falsely. Moreover they feared reprisal from the offender. This evidence suggests that most women feel helpless to retaliate the offender for fear of double victimization as the existing social patterns which have biased norms against women, demoralise them and do not leave any room for them to retaliate the offenders because they are men who are at liberty to cause further harm to the victims who retaliate.

As is revealed by Table 13, $100 \%$ respondents who retaliated to eve-teasing reported only verbal retaliation when assaulted physically and $7.3 \%$ of them retaliated, though only verbally, in the incidence of verbal and gestural teasing also; all they could do was to rebuke the offender and none of the respondents had ever gathered the courage to retaliate physically. Regarding the consequences of their retaliation, $100 \%$ of these respondents were of the view that sometimes their retaliation paid them and they succeeded in getting rid of the offender; but at times they had to pay for their retaliation for the offender was so cunning to put back the blame on the victim, thus subjecting her to censure.

Many of the factors bearing on women's decisions of not retaliating eve-teasers also deter them from seeking the help of police; these factors revealed by $100 \%$ respondents include fear of humiliation, embarrassment and of being stigmatised and, the fear of reprisal or reversal of blame from the offender (Table 14). $28 \%$ respondents reported that though they would never think of approaching the police for the above reasons, but in severe incidence of violence when they think of doing so, the police would not be available on the spot to help them.

As is revealed in Table 15, $100 \%$ respondents were of the view that though no woman is spared especially in physical teasing even if she is covered fully, if a woman wears clothes which highlight/expose body features, its inevitable consequence is that she would have to face 
Table 14. Reasons for not seeking the help of police.

\begin{tabular}{llcc}
\hline S/N & Reasons & Frequency & $\%$ \\
\hline $1 . \quad$ Fear of humiliation, embarrassment and stigma and Fear of reprisal & 300 & 100 \\
& or reversal of blame from the offender & 84 & 28 \\
2. & Police not available when needed & 300 & 100 \\
\hline
\end{tabular}

Table 15. Views about whether wearing revealing outfits increase a woman's vulnerability to sexual violence.

\begin{tabular}{llcc}
\hline S/N & Responses & No. of respondents & $\%$ \\
\hline 1. & Yes & 300 & 100 \\
2. & No & 0 & 0 \\
Total & & 300 & 100 \\
\hline
\end{tabular}

Table 16. Views about which group of women is more vulnerable to Verbal and gestural teasing.

\begin{tabular}{llcc}
\hline S/N & Responses & No. of respondents & $\%$ \\
\hline 1. & Responsive & 300 & 100 \\
2. & poker-faced (expressionless) & 0 & 0 \\
Total & & 300 & 100 \\
\hline
\end{tabular}

eve teasing in every form. As they had experienced and observed, all respondents thought that this factor certainly increases a woman's vulnerability to verbal, gestural as well as physical teasing.

As is revealed in Table 16, $100 \%$ respondents were of the opinion, - that no woman is immune to eve teasing but if a woman appears to be responsive to the eve teaser, she would be more vulnerable to verbal and gestural teasing because such type of teasing is mostly intended by the offenders, to extract response from women, to derive pleasure out of it and, is reckoned by them as their triumph over women; therefore looking poker-faced (those who do not reveal any expression) is an effective strategy which protects women, to some extent, from becoming easy targets to verbal and gestural eve teasers. But to subject oneself to such constraints where even your expressions are to be controlled is a physical as well as mental torment for women. This can only be described as a systematic assault on their fundamental right to free movement.

As is revealed in Table 17, $100 \%$ respondents held the opinion that the women who look timid are easy targets of physical teasing as this offence is committed underhandedly and the offenders fear disclosure by the victim. As a result, they prefer timid victims whom they perceive too fearful to react and disclose the offence; therefore looking bold is an effective strategy which protects women, to some extent, from being easy targets to physical eve teasers.

The above findings suggest that certain psychological factors are related to the nature of violence and have an impact on the degree of vulnerability of women to violence.

\section{CONCLUSION AND SUGGESTIONS}

The empirical study shows that eve teasing is rampant and it grabs a girl's childhood from her while making her learn to avoid victimization irrespective of the social class to which she belongs.

Women move through various stages of abuse, the duration and intensity of abuse depends on their age; while teenagers are subjected to intense abuse (especially verbal and gestural) Whilst the frequency and intensity of verbal and gestural teasing tend to decrease 
Table 17. Views about which group of women is more vulnerable to physical teasing.

\begin{tabular}{lccl}
\hline S/N & Responses & No. of respondents & $\%$ \\
\hline 1. & Timid & 300 & 100 \\
2. & Bold-looking & 0 & 0 \\
Total & & 300 & 100 \\
\hline
\end{tabular}

with increasing age, there is no significant decrease in the frequency and intensity of physical abuse especially on buses; it is only at the stage of their middle age that the frequency as well as the intensity of physical abuse get significantly diminished.

Women are not safe in any social setting; they are denied free movement wherever they go. They are victimised on buses, busy markets, inside and outside educational institutions, at picnic spots and are not spared even in social gatherings like marriages etc.

Physical intimacy on buses and on busy roads / markets and the other types of eve teasing like, singing obscene songs, unwelcome sexual jokes, remarks about female body, showing obscene gestures, winking, whistling, staring and stalking and obscene and suggestive words uttered on the telephone or by obscene messages sent on the cell phones or through internet were freely reported by the respondents; but the incidents of molestation (forced and outright groping) were highly underreported, keeping in view the police records of molestation cases in Srinagar District (which exceed the recorded eve teasing cases). The obvious reason for this is that it would attach stigma to them and would be embarrassing for them to report such incidents. According to police sources, molestation or even eve teasing cases are rarely reported by the victims themselves who usually manage to escape the situation; such cases either come directly to the notice of the policemen on duty or are reported by nearby people.

Whilst men belonging to all age groups and socioeconomic and educational backgrounds may constitute the perpetrators of sexual violence against women, there is a close association between age, educational and socio-economic factors and the nature of violence; younger age is associated with greater verbal and gestural teasing perpetration and victimisation, and its frequency tends to decrease with increasing age. Verbal and gestural eve-teasing is much glorified by media and the message sent is that it is more desirable and suitable for teenagers and young adults and, humorous and ridiculous if committed by middle aged people. But diminishing frequency of verbal and gestural teasing is replaced by the escalation in physical teasing (committed stealthily in buses and on busy roads) as the perpetrators enter middle age. Therefore there is a positive asso-ciation between physical teasing perpetration and middle age.

Whilst eve teasing occurs across all social and economic groupings, a significant association is observed between physical teasing and the low educational and social status of perpetrators; but as far as the verbal and gestural teasing is concerned, men belonging to all educational and socio-economic backgrounds tend to perpetrate this type of violence, though there is evidence that men of lower socio-economic and educational status tend to perpetrate more frequent and demeaning violence than their higher status counterparts.

Majority of women usually let the verbal or gestural teasing to go unrecognized, and only a few retaliate (though only verbally) in the event of verbal or gestural teasing; and while many women retaliate to physical teasing (though only verbally), many others employ the strategy of remaining silent and somehow manage to escape the situation to protect themselves which makes women feel like living in a prison created by the eve teasers who are of course men. Retaliation, sometimes pays them and they succeed in getting rid of the offender but at times they have to pay for their retaliation if the offender is so cunning to put back the blame on the victim thus subjecting her to censure.

Most women do not retaliate to verbal or gestural teasing as it invites humiliation and embarrassment for them and people put blame on them for having done "something wrong" to invite the eve teaser for committing the offence and they also fear reprisal from the offender which may be detrimental for the victim. Moreover, the retaliation is not a one-off event; it is a matter of daily affair which becomes another mental torment for women. Some women perceive that verbal or gestural teasers like to be rebuked and they always try to extract response from the victim because they take it wrongly as the message of approval on the part of the victim which encourages them for further teasing. Besides other reasons, women fear that if the offender escapes responsibility by taking benefit of doubt about his offence due to hustle of jam-packed buses and markets and the offender might even reverse the blame on the victim that she was asking and when the man (offender) refused to comply, she accused him falsely. The threat of double victimisation in all cases causes women to endure the violence while rarely resisting it as the existing social patterns which have biased norms against women demoralise them and do not leave any room for them to retaliate the offenders because they are men who are at liberty to cause further harm to the victims who retaliate.

Most women have the perception through their experience that though no woman is spared especially in case of physical teasing even if she is covered fully but if a woman puts on revealing outfits, its inevitable 
consequence is that she would have to face intense eve teasing in every form. Certain psychological factors are also related to the nature of violence and have an impact on the degree of vulnerability of women to violence; the woman, who appears to be responsive to the eve teaser, becomes more vulnerable to verbal and gestural teasing because such type of teasing is mostly intended by the offenders to extract response from women, to derive pleasure out of it and, is reckoned by them as their triumph over women; therefore looking poker-faced is an effective strategy which protects women, to some extent, from being easy targets to verbal and gestural eve teasers. But to subject oneself to such constraints where even your expressions are to be controlled is a physical as well as mental torment for women. This can only be described as a systematic assault on their fundamental right to free movement. Moreover, women who look timid are perceived to be easy targets to the offenders of physical teasing as this offence is committed underhandedly and the offenders fear disclosure by the victim so they prefer timid victims whom they perceive too fearful to react and disclose the offence; therefore looking bold is an effective strategy which protects women, to some extent, from being easy targets to physical eve teasers.

Eve teasing can be perceived as an outgrowth of the gender biased socialization process and a mechanism by which men assert power and dominance over women.

It is not only the experience of violence but more importantly the fear of violence which affects women in every sphere of life. Fear and experience of sexual violence is a permanent constraint on the mobility of women and limits their access to resources and basic activities and erodes self confidence and self esteem of women and they lose the confidence to step out of the house while learning to avoid being victimised.

Therefore, certain measures at the family, societal, legal and personal level are needed to combat this problem. Socialisation and social control at the family and social level should not be gender biased; men should not be given undue freedom and power and a sense of accountability should be inculcated in men - the moral sanctions which are imposed on girls to be protected from the ill consequences of the unlimited freedom given to boys, if only half of them are imposed on boys, the girls would regain their personhood and integrity by enjoying enough freedom to live like free human beings. Further, media should not portray men as powerful and women as powerless, vulnerable and in a position to be exploited; and it should not project women as sex objects and (especially cinema) should not portray eve-teasing as something harmless. Media should raise slogans against this evil and should make aware people about the seriousness of this issue. Religious values should be imbibed so that the factors, which cause moral degeneration, are counterbalanced by moral values provided by religion.

At the legal level, strict implementation of regulations prohibiting overloading on buses and maintenance of separate seats reserved in buses for women would be very effective measure for protecting them from physical assault; police should perform their duty honestly and special police forces should be employed for such offences which would take on spot action and more importantly would serve the purpose of putting constraints to potential offenders. Whosoever is found guilty must be punished. As far as the remedial measures at personal level are concerned, women should avoid wearing indecent and revealing outfits. But if a woman is indecent (though she is responsible for increasing her vulnerability to sexual violence), it is by no way a justification for men to assault her; after all men are social beings and not animals to give the justification that they assaulted a woman because she was an easy prey to them. Moreover, if religious teachings are to be followed where men are not even allowed to take a second glance of a woman (which is the most forgotten religious teaching), men would not be able to justify their violence by finding faults with women.

\section{REFERENCES}

Bunch C (1997). The intolerable status quo: Violence against Women and Girls The Progress of Nations. Retrieved from http://www.unicef.org/pon97/women1c.htm.

Davis K, Dickey J, Stratford T (ed) (1987). Out of Focus: Writings on Women and the Media, London.

Gender Study Group, (1996).A Report on Sexual Harassment in Delhi University. Delhi.

Heise L (1992). "Violence Against Women: The Missing Agenda", Women's Health: A Global Perspective, Westview Press.

Kapur ML (1992). Social and Economic History of J and K State, Anmol Publications, Jammu.

Krug E, Dahlberg L, Mercy J, Zwi A, Lozano R (2002). World report on violence and health. Geneva: WHO.

Mehrotra D (1982). Sexual harassmen, PUCL Bulletin, Retrieved at http://www.pucl.org/from-archives/Gender/harassment.htm.

Poudyal R (2000). Alternative masculinities in South Asia: an exploration through films for schools. IDS Bulletin 31(2):75-78.

Ramasubramayam S, Beth OM (2003). Portrayals of sexual violence in popular Hindi films, 1997-99, Sex Roles: A Journal of Research at http://www.findarticles.com/p/articles/mi_m2294/is_2003_April/ai_101 174063.

Shah G (2000). Crime against Women and Police, New Delhi.

The United Nations (1993). Declaration on the Elimination of Violence against Women, General Assembly Resolution. 